\title{
An elementary derivation of Hattendorff's theorem
}

\author{
Elias S. W. Shiu ${ }^{1}$ (D) Xiaoyi Xiong ${ }^{2}$
}

Received: 21 November 2020 / Revised: 7 December 2020 / Accepted: 9 December 2020 /

Published online: 5 January 2021

(c) The Author(s) 2021

\begin{abstract}
For a general fully continuous life insurance model, the variance of the loss-atissue random variable is the expectation of the square of the discounted value of the net amount at risk at the moment of death. In 1964 Jim Hickman gave an elementary and elegant derivation of this result by the method of integration by parts. One might expect that the method of summation by parts could be used to treat the fully discrete case. However, there are two difficulties. The summation-by-parts formula involves shifting an index, making it somewhat unwieldy. In the fully discrete case, the variance of the loss-at-issue random variable is more complicated; it is the expectation of the square of the discounted value of the net amount at risk at the end of the year of death times a survival probability factor. The purpose of this note is to show that one can indeed use the method of summation by parts to find the variance of the loss-at-issue random variable for a fully discrete life insurance policy.
\end{abstract}

Keywords Loss at issue $\cdot$ Hattendorff's theorem $\cdot$ Summation by parts $\cdot$ Net amount at risk

The celebrated Hattendorff Theorem [6] in life contingencies is perhaps best viewed as an application of the result that increments of a martingale over disjoint time intervals are uncorrelated [3]. The purpose of this note is to present an elementary derivation of a version of the theorem. The word "elementary" is used in the sense that the key tool in the derivation is the technique of summation by parts.

We consider the model, presented in Sect. 7.4 of [1] and also in Sect. 5.5 of [4], of a general fully discrete life insurance on $(x)$. For $j=1,2,3, \ldots$, the death benefit in the $j$ th policy year is $b_{j}$, payable at time $j$, which is the end of the policy

Elias S. W. Shiu

elias-shiu@uiowa.edu

Xiaoyi Xiong

xiaoyixiong71@gmail.com

1 Department of Statistics and Actuarial Science, University of Iowa, Iowa City, IA, USA

2 Transamerica Life Insurance Company, Plano, TX, USA 
year; the premium paid in the $j$ th policy year is $\pi_{j-1}$, payable at time $j-1$, which is the beginning of the policy year. Let $K_{x}$ denote the curtate future lifetime of $(x)$; for simplicity, we shall use $K$ for $K_{x}$. The insurer's loss at issue random variable is

$$
L:=v^{K+1} b_{K+1}-\sum_{j=0}^{K} v^{j} \pi_{j}
$$

For $j=0,1,2, \ldots$, let ${ }_{j} V$ denote the reserve of the policy at time $j$; also, define

$$
\rho(j):=v^{j+1}\left(b_{j+1}-{ }_{j+1} V\right),
$$

the present value of the net amount at risk at the end of policy year $j+1$. The version of Hattendorff's Theorem that we shall derive is

$$
\operatorname{Var}[L]=\mathrm{E}\left[[\rho(K)]^{2} \times p_{x+K}\right] .
$$

Note that we do not necessarily assume ${ }_{0} V=0$.

Derivation: It follows from the reserve recursion formula,

$$
{ }_{j} V+\pi_{j}=v\left({ }_{j+1} V p_{x+j}+b_{j+1} q_{x+j}\right),
$$

that

$$
v^{j} \pi_{j}=\Delta\left(v_{j}^{j} V\right)+\rho(j) q_{x+j},
$$

where $\Delta$ denotes the forward difference operator. Applying (3) to Eq. (1) yields

$$
L=v^{K+1} b_{K+1}-\sum_{j=0}^{K}\left[\Delta\left(v_{j}^{j} V\right)+\rho(j) q_{x+j}\right] .
$$

Because

$$
\sum_{j=0}^{K} \Delta\left(v_{j}^{j} V\right)=v^{K+1}{ }_{K+1} V-v_{0}^{0} V=v_{K+1}^{K+1} V-\mathrm{E}[L],
$$

Eq. (4) can be rewritten as

$$
\begin{aligned}
L-\mathrm{E}[L] & =\rho(K)-\sum_{j=0}^{K} \rho(j) q_{x+j} \\
& =\rho(K)-\varphi(K),
\end{aligned}
$$

with the definition

$$
\varphi(k):=\sum_{j=0}^{k} \rho(j) q_{x+j}, \quad k=0,1,2, \ldots
$$


By (5),

$$
\begin{aligned}
\operatorname{Var}[L] & =\mathrm{E}\left[[\rho(K)-\varphi(K)]^{2}\right] \\
& =\mathrm{E}\left[[\rho(K)]^{2}\right]+E\left[[\varphi(K)]^{2}\right]-2 E[\rho(K) \varphi(K)] .
\end{aligned}
$$

Thus, deriving formula (2) is equivalent to showing

$$
\mathrm{E}\left[[\varphi(K)]^{2}\right]=2 \mathrm{E}[\rho(K) \varphi(K)]-\mathrm{E}\left[[\rho(K)]^{2} q_{x+K}\right] .
$$

Because $\operatorname{Pr}[K=k]={ }_{k} p_{x}-{ }_{k+1} p_{x}=-\Delta_{k} p_{x}$,

$$
\mathrm{E}\left[[\varphi(K)]^{2}\right]=-\sum_{k=0}^{\infty}[\varphi(k)]^{2} \Delta_{k} p_{x} .
$$

To evaluate (8), we use the summation-by-parts formula,

$$
\sum_{k=m}^{n} g(k) \Delta h(k)=\left.g(k) h(k)\right|_{k=m} ^{k=n+1}-\sum_{k=m}^{n} h(k+1) \Delta g(k) .
$$

Hence,

$$
\begin{aligned}
\mathrm{E}\left[[\varphi(K)]^{2}\right] & =-\left.[\varphi(k)]_{k}^{2} p_{x}\right|_{k=0} ^{k=\infty}+\sum_{k=0}^{\infty}{ }_{k+1} p_{x} \Delta\left([\varphi(k)]^{2}\right) \\
& =[\varphi(0)]_{0}^{2} p_{x}+\sum_{k=0}^{\infty}{ }_{k+1} p_{x}\left([\varphi(k+1)]^{2}-[\varphi(k)]^{2}\right) .
\end{aligned}
$$

From (6),

$$
\varphi(k)=\varphi(k+1)-\rho(k+1) q_{x+k+1}, \quad k=0,1,2, \ldots,
$$

which implies

$$
[\varphi(k+1)]^{2}-[\varphi(k)]^{2}=2 \varphi(k+1) \rho(k+1) q_{x+k+1}-\left[\rho(k+1) q_{x+k+1}\right]^{2} .
$$

With $_{k+1} p_{x} \times q_{x+k+1}=\operatorname{Pr}[K=k+1]$, the series on the right-hand side of Eq. (9) is

$$
\begin{aligned}
& \sum_{k=0}^{\infty}\left([\varphi(k+1)]^{2}-[\varphi(k)]^{2}\right)_{k+1} p_{x} \\
& \quad=\sum_{k=0}^{\infty} 2 \varphi(k+1) \rho(k+1) \operatorname{Pr}[K=k+1]-\sum_{k=0}^{\infty}[\rho(k+1)]^{2} q_{x+k+1} \operatorname{Pr}[K=k+1] \\
& \quad=2\left\{\mathrm{E}[\varphi(K) \rho(K)]-\varphi(0) \rho(0) q_{x}\right\}-\left\{\mathrm{E}\left[[\rho(K)]^{2} q_{x+K}\right]-[\rho(0)]^{2}\left(q_{x}\right)^{2}\right\} \\
& \quad=2 \mathrm{E}[\varphi(K) \rho(K)]-\mathrm{E}\left[[\rho(K)]^{2} q_{x+K}\right]-[\varphi(0)]^{2}
\end{aligned}
$$

because $\rho(0) q_{x}=\varphi(0)$. It follows from (9) and (10) that we have derived (7). Thus we have presented an elementary derivation of formula (2). 
Remarks (i) We were motivated to seek this summation-by-parts derivation because there is a rather straightforward integration-by-parts derivation in the fully continuous case $[5,7]$. Let $T_{x}$ denote the future lifetime of $(x)$. The fully continuous analogues of (1) and (2) are

$$
L=v^{T_{x}} b_{T_{x}}-\int_{0}^{T_{x}} v^{t} \pi_{t} \mathrm{~d} t
$$

and

$$
\operatorname{Var}[L]=\mathrm{E}\left[\left[v^{T_{x}}\left(b_{T_{x}}-{ }_{T_{x}} V\right)\right]^{2}\right],
$$

respectively. To derive (12), we apply the following form of Thiele's differential equation,

$$
v^{t} \pi_{t} \mathrm{~d} t=\mathrm{d}\left(v^{t}{ }_{t} V\right)+v^{t}\left(b_{t}-{ }_{t} V\right) \mu_{x+t} \mathrm{~d} t,
$$

to $(11)$, yielding

$$
L=v^{T_{x}} b_{T_{x}}-\int_{0}^{T_{x}} \mathrm{~d}\left(v^{t}{ }_{t} V\right)-\int_{0}^{T_{x}} v^{t}\left(b_{t}-{ }_{t} V\right) \mu_{x+t} \mathrm{~d} t .
$$

Because $\int_{0}^{T_{x}} \mathrm{~d}\left(v^{t}{ }_{t} V\right)=v^{T_{x}} T_{x} V-v^{0}{ }_{0} V=v^{T_{x}} T_{x} V-\mathrm{E}[L]$, we obtain

$$
L-\mathrm{E}[L]=v^{T_{x}}\left(b_{T_{x}}-{ }_{T_{x}} V\right)-\int_{0}^{T_{x}} v^{t}\left(b_{t}-{ }_{t} V\right) \mu_{x+t} \mathrm{~d} t .
$$

Hence (12) is proved if we can show that the expectation of the square of the righthand side of (13) is

$$
\mathrm{E}\left[\left[v^{T_{x}}\left(b_{T_{x}}-{ }_{T_{x}} V\right)\right]^{2}\right] .
$$

This is equivalent to showing

$$
\mathrm{E}\left[\left[\int_{0}^{T_{x}} v^{t}\left(b_{t}-{ }_{t} V\right) \mu_{x+t} \mathrm{~d} t\right]^{2}\right]=2 \mathrm{E}\left[v^{T_{x}}\left(b_{T_{x}}-{ }_{T_{x}} V\right) \times \int_{0}^{T_{x}} v^{t}\left(b_{t}-{ }_{t} V\right) \mu_{x+t} \mathrm{~d} t\right] .
$$

Equation (14), simpler than its discrete analogue (7), can be readily verified by an integration by parts, as shown on page 43 of [5].

(ii) One may better understand (5) by noting that $\rho(j) q_{x+j}$ is the present value of the cost of insurance based upon the net amount at risk for policy year $(j+1)$.

(iii) Formula (2) is particularly useful if the death benefit, payable at the end of the year of death, is a face amount plus the reserve, because the net amount at risk is then just the face amount. (The face amount can be allowed to change from year to year.) Type B Universal Life insurance policies have such death benefits [2, 8].

(iv) As noted above, we do not necessarily assume ${ }_{0} V=0$. For $j=0,1,2, \ldots$, let 


$$
{ }_{j} L:=v^{K_{x+j}+1} b_{j+K_{x+j}+1}-\sum_{k=0}^{K_{x+j}} v^{k} \pi_{j+k}
$$

be the time- $j$ prospective loss random variable; this is (7.4.4) in [1]. Then,

$$
\mathrm{E}\left[{ }_{j} L\right]={ }_{j} V
$$

see (7.4.5) in [1]. Formula (2) is generalized as

$$
\operatorname{Var}\left[{ }_{j} L\right]=\mathrm{E}\left[\left[v^{K_{x+j}+1}\left(b_{j+K_{x+j}+1}-{ }_{j+K_{x+j}+1} V\right)\right]^{2} \times p_{x+j+K_{x+j}}\right] .
$$

Acknowledgements Elias S. W. Shiu gratefully acknowledges the support from the Principal Financial Group.

Open Access This article is licensed under a Creative Commons Attribution 4.0 International License, which permits use, sharing, adaptation, distribution and reproduction in any medium or format, as long as you give appropriate credit to the original author(s) and the source, provide a link to the Creative Commons licence, and indicate if changes were made. The images or other third party material in this article are included in the article's Creative Commons licence, unless indicated otherwise in a credit line to the material. If material is not included in the article's Creative Commons licence and your intended use is not permitted by statutory regulation or exceeds the permitted use, you will need to obtain permission directly from the copyright holder. To view a copy of this licence, visit http://creativecommons.org/licen ses/by/4.0\%.

\section{References}

1. Bowers NL, Gerber HU, Hickman JC, Jones DA, Nesbitt CJ (1986) Actuarial mathematics. Society of Actuaries, Itasca

2. Dickson DCM, Hardy MR, Waters HR (2020) Actuarial mathematics for life contingent risks, 3rd edn. Cambridge University Press, Cambridge

3. Gerber HU (1979) An introduction to mathematical risk theory. Huebner Foundation Monograph 8, distributed by Irwin, Homewood

4. Gerber HU (1997) Life insurance mathematics, 3rd edn. Springer, Berlin

5. Gerber HU, Leung BP, Shiu ESW (2003) Indicator function and Hattendorff theorem. N Am Actuar J 7(1):38-47

6. Hattendorff K (1868) Das Risiko bei der Lebensversicherung. E. A. Masius' Rundschau der Versicherungen 18:169-183

7. Hickman JC (1964) A statistical approach to premiums and reserves in multiple decrement theory. Trans Soc Actuar 16:1-16 (Discussion 149-154)

8. Promislow SD (2015) Fundamentals of actuarial mathematics, 3rd edn. Wiley, Chichester

Publisher's Note Springer Nature remains neutral with regard to jurisdictional claims in published maps and institutional affiliations. 